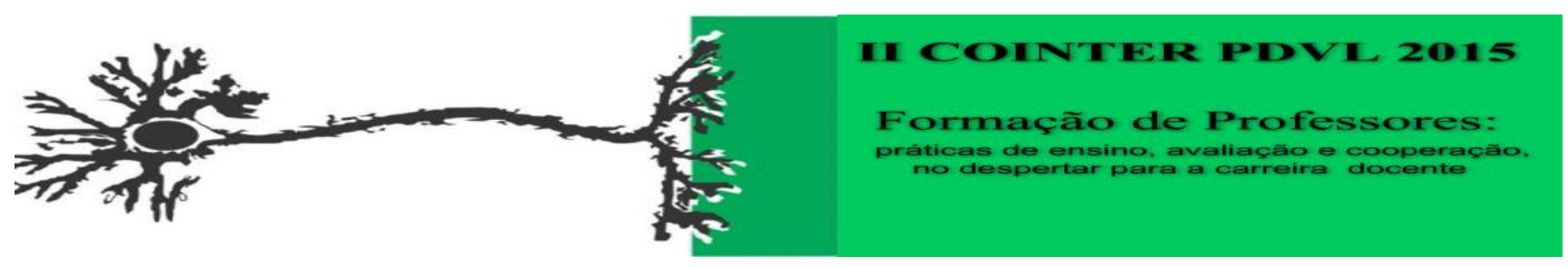

\title{
JOGOS EDUCATIVOS COMO SUPORTE PARA ALFABETIZAÇÃO
}

\author{
Apresentação: Comunicação Oral \\ Darielle Débora RODRIGUES ${ }^{1}$; Darília Cecília Belarmino RODRIGUES ${ }^{2}$; Reginila \\ Estelita da SILVA ${ }^{3}$; Natália Maria da SILVA ${ }^{4}$
}

\section{Resumo:}

Este artigo tem como principal objetivo refletir sobre a importância dos jogos no processo ensino-aprendizagem na alfabetização. O enquadramento teórico desta pesquisa assenta-se nas ideias de: Maciel (2008), Piaget (1978), Soares (2001),Vygotsky (1984), Neto ( 1996), Santos ( 2000) entre outros. De acordo com o que foi pesquisado sobre o tema, os jogos são atividades indispensáveis na sala de aula, pois trazem inúmeros benefícios para a aprendizagem da criança, salientando que o jogo não deve ser visto apenas como divertimento ou brincadeira para gastar energia, pois eles contribuem de maneira positiva no processo ensino-aprendizagem, favorecendo o desenvolvimento mental, motor e social da criança se utilizado de maneira correta. A alfabetização é fundamental na formação dos indivíduos pois é nessa fase que os discentes apropriam-se da leitura e escrita; por este motivo o jogo não deve ser praticado como uma forma de ocupação do tempo ocioso, o mesmo deve ter um objetivo $\mathrm{O}$ jogo pelo jogo não tem valor, para os participantes será perda de tempo. No que se refere à metodologia, ressalta-se que esta é uma investigação de caráter qualitativo focando leitura. Com base nos resultados obtidos percebe-se que o jogo é uma atividade indispensável na alfabetização e quando usado corretamente cria momentos significativos e agradáveis com a leitura e a escrita na sala, . Conclui-se, portanto, que é função da escola trabalhar o caminho da alfabetização de forma prazerosa, para que o aluno aprenda a exercer a leitura e escrita em diferentes situações sociais que ele terá contato no decorrer de sua vida.

Palavras-chave: Jogo, Ensino-aprendizagem, Alfabetização.

\section{Introdução}

\footnotetext{
${ }^{1}$ Estudante Curso de Pedagogia da Universidade de Pernambuco, E-mail: daryelle.debora@ outlook.com

2 Estudante Curso de Letras da Universidade de Pernambuco/ Campus Mata Norte, E-mail: dariliacecilya_@hotmail.com

${ }^{3}$ Estudante Curso de Pedagogia da Universidade de Pernambuco, E-mail: regynilla@ @otmail.com.br

4 Estudante Curso de Pedagogia da Universidade de Pernambuco/ Campus Mata Norte, silva.n.mda@gmail.com
} 
A alfabetização é a fase inicial da leitura e escrita, nesse período a criança está no processo de formação intelectual pessoal e ele geralmente começa na escola (MACIEL e LÚCIO, 2008). Ser alfabetizado é um direito de todo cidadão, hoje em dia existe a preocupação de alfabetizar letrando, SOARES (2001), afirma que tratar a alfabetização na perspectiva do letramento, seria proporcionar a construção de habilidades para o exercício efetivo e competente da tecnologia da escrita. Diante deste tema tão abrangente que é a alfabetização, destaca-se o desenvolvimento da habilidade na leitura, escrita e o letramento. Como sabemos cada criança tem seu ritmo de aprendizagem, sendo assim não existe idade padrão para aquisição da leitura, podendo esta acontecer entre os 4 á 7 anos de idade. A prática da leitura também está ligada pelo estímulo que a criança tem para o desenvolvimento da mesma, ou seja, o contato com livros, jornais, revistas e jogos que estejam adequados a realidade dos educandos trará resultados significativos.

Para Ferreiro ”nenhuma prática pedagógica é neutra. Todas estão apoiadas em certo modo de conceber o processo de aprendizagem e o objeto dessa aprendizagem" (1985,p.31).

O professor deve transmitir os conteúdos de maneiras atrativas e dinâmicas, possibilitando uma linguagem linear entre ele e os alunos. Os jogos desperta na criança o desejo de aprender, pois eles já fazem parte do universo da criança, ou seja, é preciso utilizar as brincadeiras como ferramenta que possibilite a aquisição do conhecimento; na tentativa de formar cidadãos capacitados para atuar na sociedade na qual estão inseridos, onde a alfabetização se torna ferramenta indispensável na interferência de um mundo "inteligente".

\section{A importância dos jogos para educação}

De acordo com Piaget (1990) o pensamento e desenvolvimento da criança é diferenciado da fase adulta, segundo ele a criança só reconhece um objeto fisicamente, quando entra em contato com o mesmo e descobre o seu comportamento durante as suas interações. O conhecimento seria construído então no manuseio, ou seja, no contato que ela teve com o objeto. 
O jogo é um recurso que desenvolve habilidades, Rodrigues ( 2010 p.18) fala que "O jogo envolve uma capacidade de ação por iniciativa própria, portanto o jogo é caracterizado por atitude, que corresponde a uma reação de estímulos externos, inerentes ao ser humano."

A palavra jogo vem do latim "jocus" e significa brincadeira e divertimento. $\mathrm{O}$ jogo é considerado como uma atividade física ou intelectual que integra um sistema de regras e define um indivíduo (ou um grupo) vencedor e outro perdedor.

É impossível imaginar uma infância, sem risos, brincadeiras e sonhos. Quando falamos em educação de crianças é triste saber que ainda existe sala de aula com cadeiras enfileiradas, paredes sem vidas e conteúdos ditadores, lugares onde as crianças vivem o que Freire nomeia de educação bancária, onde os alunos são vistos como depósitos.

A educação precisa ser vista como algo atrativo, por este motivo se torna crucial o trabalho com jogos educativos na sala de aula, Piaget (1978, p. 45) "Os jogos não são apenas uma forma de entretenimento, mas meios que contribuem e enriquecem o desenvolvimento intelectual". Quando o educador trabalha o conteúdo proposto utilizando jogos, os alunos aprendem prazerosamente, pois a brincadeira já faz parte do universo da criança e ela desenvolve diversas habilidades comportamentais e quando bem elaborado, pode levar a criança a ser alfabetizada na perspectiva do letramento.

\section{Os jogos na alfabetização}

Por meio dos jogos as crianças desenvolvem diversas habilidades, tais como planejar ações, solucionar problemas, criar histórias, entre tantas outras; é preciso que o educador crie situações onde o jogo se torne um caminho para aprendizagem; no entanto os educadores em sua maioria veem o "jogo" como uma metodologia distante para a alfabetização; ficando presos a exercícios tradicionais, que muitas vezes não contribui para a formação da criança. Para Neto (1996, p.43),

Os jogos educativos são uma área que pode tornar-se alvo de inúmeras pesquisas. Se o ensino for lúdico e desafiador, a aprendizagem prolonga-se fora da sala de aula, fora da escola, pelo cotidiano, num crescimento muito mais rico do que algumas informações que o aluno decora.

O jogo pedagógico contribui para a construção do conhecimento social, pois nele o aluno aprende se divertido, deixando de lado a decoração de conceitos. 
Nota-se então que o jogo pedagógico leva a criança a uma alfabetização letrada, Freire (1991) diz que "Não basta saber ler que 'Eva viu a uva'. É preciso compreender qual a posição que Eva ocupa no seu contexto social, quem trabalha para produzir a uva e quem lucra com esse trabalho". Sendo assim a aquisição da leitura só será eficaz quando a criança interpretar aquilo que leu, fazendo uma compreensão social com a realidade na qual estão inseridos.

\section{Jogos no processo ensino/aprendizagem}

O jogo é considerado uma atividade lúdica que tem valor educacional, a utilização do mesmo no ambiente escolar traz muitas vantagens para o processo de ensino aprendizagem.

De acordo com SILVA (2004),

Ensinar por meio de jogos é um caminho para o educador desenvolver aulas mais interessantes, descontraídas e dinâmicas, podendo competir em igualdade de condições com os inúmeros recursos a que o aluno tem acesso fora da escola, ou estimulando sua vontade de frequentar com assiduidade a sala de aula e incentivando seu desenvolvimento no processo ensino e aprendizagem, já que aprende e se diverte, simultaneamente.

Através do jogo e da brincadeira a criança mobiliza a mente estimulando o pensamento, e consequentemente acontece o desenvolvimento social, motor e cognitivo.

Para Kishimoto (2004):

A utilização do jogo potencializa a exploração e a construção do conhecimento, pois conta com a motivação interna, típica do lúdico, mas o trabalho pedagógico requer a oferta de estímulos externos e a influencia de parceiros bem como a sistematização de conceitos em outras situações que não jogos. Ao utilizar de modo, metafórico, a forma lúdica (objeto suporte de brincadeira) para estimular a construção do conhecimento.

O jogo só será considerado um recuso pedagógico se for aplicado com um objetivo específico; se o educador preparar a base, estabelecendo regras do jogo na perspectiva do letramento terá bons resultados, hoje em dia a internet disponibiliza um mundo de informações, existe diversos jogos educativos que podem ser confeccionados em casa, é necessário que o educador desperte o seu lado criativo e se torne um profissional pesquisador. Só assim será capaz de formar cidadãos consciente, crianças que possam interferir no mundo que o cerca por meio da leitura e escrita. 


\section{Procedimentos metodológicos}

Este estudo foi orientado pela abordagem qualitativa de pesquisa, com ênfase na pesquisa-ação. Para a coleta de dados foi utilizado a aplicação de um jogo do boliche silábico; a atividade foi realizada no colégio Municipal Presidente Tancredo De Almeida Neves, o jogo foi elaborado com materiais alternativos:, garrafas pet e pequenos recortes com silabas/letras, o mesmo foi aplicado no $1^{\circ}$ ano da educação fundamental com a presença de 15 alunos.

\section{Resultados e Discussão}

Com o intuito de conhecer um pouco mais a respeito da abordagem dos jogos no ensino da leitura e escrita, realizamos uma intervenção com os alunos da escola que serviu de lócus a esta investigação e aplicamos um jogo no qual foi solicitado a leitura e a organização silábica para formação de palavras, utilizamos sílabas que as crianças já conheciam, elas formavam palavras que estavam presentes no cotidiano da criança, como: bola, boneca, comida etc; o jogo foi intitulado de: "Boliche silábico".

Iniciamos o jogo com uma roda de conversa, para esclarecer as regras do jogo. A atividade foi aplicada numa turma de $1^{\circ}$ ano, com a presença de 15 estudantes.

Os dados revelaram que o trabalho com jogos levam os educandos a ler de forma prazerosa, como possibilita a demonstração da criatividade de cada educando.

Santos (2000, p.37), afirma que,

O jogo na escola ganha espaço, como ferramenta ideal da aprendizagem, na medida em que propõe estímulo ao interesse do aluno, desenvolve níveis diferentes de sua experiência pessoal e social, ajuda-o a descobrir novas descobertas, desenvolve e enriquece sua personalidade e simboliza um instrumento pedagógico que leva ao professor a condição de condutor, estimulador e avaliador da aprendizagem.

E assim sendo, com base no pensamento de Santos fizemos algumas inferências sobre a vivência do jogo aplicado com os estudantes.

No momento da aplicação do jogo as garrafas foram posicionadas, uma ao lado da outra, os alunos foram organizados em uma fila decrescente, a medida que derrubavam as garrafas, este possuía um quantitativo de sílaba, organizava a mesma descobrindo assim palavras, observe as imagens abaixo: 
Figura 1 - Jogo do boliche silábico

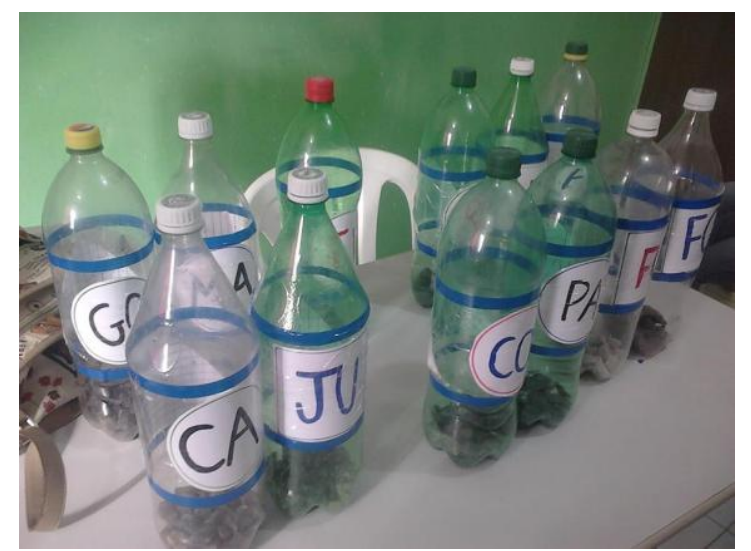

Fonte: Darília C. Belarmino Rodrigues

Figura 3- Momento do jogo

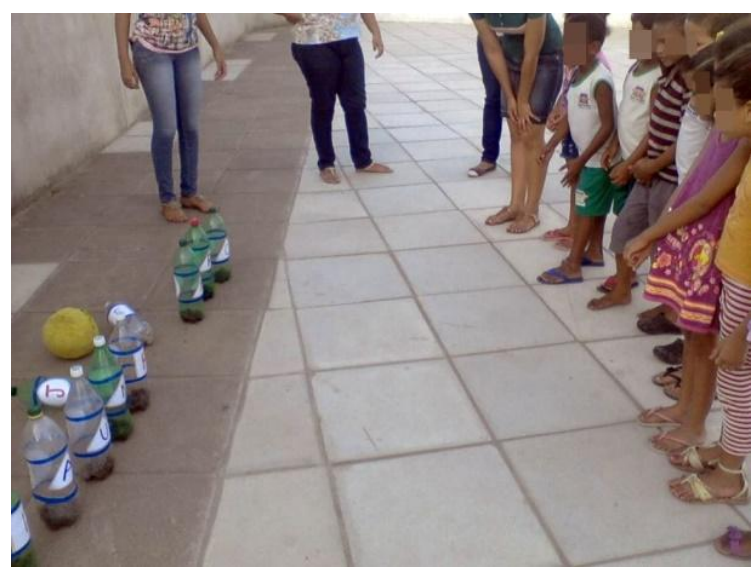

Fonte: Darília Cecília B. Rodrigues
Figura 2- Aplicação do jogo

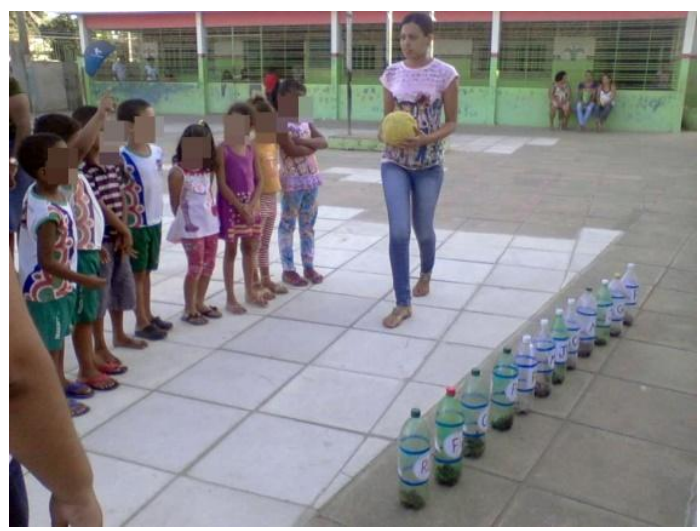

Fonte: Darília C. Belarmino Rodrigues

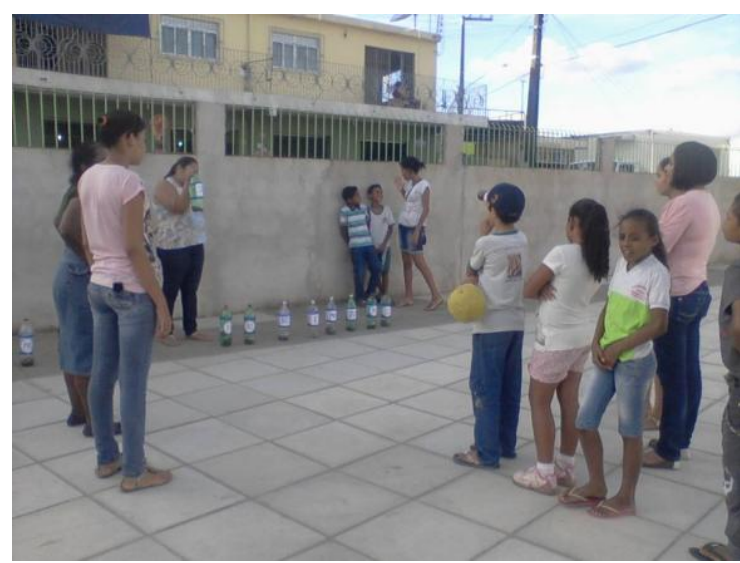

Fonte: Darília Cecília B. Rodrigues

A primeira figura mostra o jogo do boliche silábico; a segunda imagem retrata 0 momento da explicação da regra do jogo, na quarta imagem notamos o momento que a criança participa do jogo, na quarta imagem ele ler algumas palavras que podem ser formadas pelas sílabas que continham nas garrafas derrubadas. 12 alunos conseguiram desenvolver o objetivo proposto pelo jogo. Esses educandos foram participativos e colaboradores, espontaneamente formaram palavras como: FOME, CAJU, JACA, CAPA, JOGO, FOCA, PATO, VACA e reconheceram os fonemas das mesmas, eles 
também sugeriram a formação de outras palavras e expressaram o conhecimento de outras letras e sílabas que não continha no jogo.

Como a aprendizagem não é homogênea e cada criança tem um tempo pessoal para aquisição da leitura ( MACIEL e LUCIO 2008), houve 3 crianças que não conseguiram relacionar os fonemas das sílabas para a construção de palavras, estas apenas leram as letras que possuíam nas garrafas.

Ressaltamos que o ensino dos jogos educativos para alfabetização promove a interação dos discentes com a oralidade, leitura, organização de pensamento e respeito ao próximo. Convém referir que, por vezes, pode ser mais eficiente a adaptação de um jogo que já faz parte do mundo da criança do que de repente apenas escrever palavras soltas, decodificando fatos desconhecidos, construindo palavras que não têm significado nenhum na realidade do sujeito. É necessário fazer um trabalho pedagógico que estimule a curiosidade do educando, despertando no mesmo o prazer de aprender a ler e escrever.

\section{Conclusões}

Conforme os estudos realizados concluímos que hoje o ensino não se limita apenas a sala de aula, pelo contrário ele vai além, os professores precisam utilizar de práticas que desenvolvam nos alunos interesse e o prazer em aprender. "Os jogos são brincadeiras e ao mesmo tempo meios de aprendizagem" (PIAGET,1978, p. 87). Os jogos torna o processo ensino aprendizagem mais prazeroso, além de permitir um desenvolvimento amplo e significativo.

Somos cientes que ensinar é um grande desafio pois são muitas as dificuldades que os professores enfrentam em sala de aula, afinal não existem indivíduos homogêneos, sendo assim uma sala é formada por diferentes cidadãos e com tal diversidade, a educação tem que lhe dá com a falta de estrutura familiar, problemas pessoais dos educandos, falta de acompanhamento dos pais no processo educativos da criança, entre tantos outros fatores, sabemos que o mais preocupante é a falta de atenção dos alunos em querer aprender; sendo assim a aprendizagem será desenvolvida rapidamente, se o educador utilizar métodos inovadores para passar os conteúdos 
propostos, por este motivo o jogo é uma ferramenta indispensável na formação do cidadão que está adquirindo a aquisição na leitura e escrita.

Nesse contexto, o professor está como mediador do processo ensino aprendizagem e os jogos podem favorecer o desenvolvimento de metodologias diferenciadas. Daí a importância de se aliar o prazer que as crianças têm de brincar com seu desenvolvimento. Para isso faz-se necessário que os professores sejam bem instruídos através de uma formação continuada específica de como trabalhar o lúdico, adquirindo assim habilidades para unir o conhecimento às brincadeiras como meio de melhorar cada vez mais o aprendizado dos alunos.

É interessante também que a escola ofereça espaços físicos adequados, não só para propiciar subsídios aos professores para o desenvolvimento das atividades, mas também ofereça as crianças um ambiente espaçoso, onde as mesmas possam interagir e desenvolver sua autonomia e estabilidade física, psicológica, intelectual e social.

\section{Referencias}

ALMEIDA, Paulo Nunes. Dinâmica lúdica jogos pedagógicos. São Paulo: Loyola. 1978.

A importância dos jogos na alfabetização de crianças: Fortaleza Disponível em <http://www.nead.fgf.edu.br/novo/material/monografias_portugues/REJANE_MARIA_ COSTA_RODRIGUES.pdf> Acesso em: 27 de outubro de 2015

FREIRE, Paulo. A educação na cidade. São Paulo: Cortez, 1991.

FREIRE, Paulo. Pedagogia da Autonomia: Saberes necessários à prática educativa. São Paulo:PAZ e Terra, 1996 (Coleção Leitura).

KISHIMOTO, Tizuco Morchida. Jogo, Brinquedo, Brincadeira e a Educação. São Paulo: Cortez, 2002.

MACIEL, Francisca Izabel. P. e LÚCIO, Iara Silva. Os conceitos de alfabetização e letramento e os desafios da articulação entre teoria e prática. In: CASTANHEIRA, Maria Lúcia, MACIEL, Francisca Isabel. P. e MARTINS, Raquel Marcia. F. (Org.). Alfabetização e letramento na sala de aula. -Belo Horizonte: Autêntica Editora: Ceale, 2008. 
NETO, CARLOS Alberto Ferreira. Mocidade e Jogo na Infância. Rio de Janeiro: Sprint, 1996

PIAGET, J. O. Nascimento da inteligência na criança. ed. Rio de Janeiro: Zahar, 1978.

Letramento no Brasil, reflexões a partir do INAF 2001. São Paulo: Global, 2001.

PIAGET, J. A psicologia da criança. Ed Rio de janeiro: Bertrand Brasil, 1998.

PIMENTA, S. G. O estágio na formação de professores: Unidade entre teoria e prática? INEP/ Relatos de pesquisa- Série documental; n²5, maio/1995, p.16-25.

SANTOS, Santa Marli Pires dos. (Org). Brinquedoteca: a criança, o adulto e o Lúdico. Petrópolis, RJ: Vozes, 2000.

SOARES, Magda. (2001) Letramento e escolarização. In: RIBEIRO, V. M. (Org.).

SILVA, Mônica. Jogos Educativos. Campinas: Papirus, 2004.

VYGOTSKY, L. 1989. A formação social da mente. São Paulo: Martins Fontes.

VYGOTSKY, L.S; LURIA, A.R. \& LEONTIEV, A.N. Linguagem, desenvolvimento e aprendizagem. São Paulo: Ícone: Editora da Universidade de São Paulo, 1998. 